\section{The School of Health Information Science at the University of Vidoria: Towards an Integrative Model for Health Informatics Education and Research}

\author{
A. Kushniruk, F. Lau, E. Borycki, D. Protti
}

School of Health Information Science, University of Victoria, Victoria, British Columbia, Canada

\section{Introduction}

Objectives: There is an increasing need for well qualified health informatics practitioners and for educational programs that produce them. Since 1981, the School of Health Information Science at the University of Victoria has delivered a range of educational programs in health informatics. The School's objective has been to produce graduates who can assume a range of roles in health informatics, induding managers, developers, researchers and evaluators of health care systems. Methods: The approach taken by the School has been to provide an integrated "holistic" approach to health informatics education that balances both theory and practice. The curriculum has emphasized interdisciplinary skills and has been based on a process of consultation with key stakeholders in both industry and academia. In addition, several new distance collaborative models for health informatics education (including a distributed MSc degree program) have been recently initiated through the University of Victoria with collaborating Canadian universities. Results: To date, graduates of the programs offered have become highly sought after, with the demand for graduates of the programs continually exceeding the number of graduates. The core undergraduate curriculum has recently been undergone refinement to include training in new emerging areas of health informatics. In addition, a distributed MSc program has been successfully initiated by the School, aurrently with 23 sudents participating from dispersed geographical locations across Canada. Condusions: The School of Health Information Science at the University of Victoria has been involved in providing unique interdisciplinary education in health informatics for over twenty years. The School continuestomaintain its emphasison integrated education, refining its curriculum and moving into new areas such as distance education and cross-Canadian collaborations. HauxR, Kulikowski C editors. IMIA Yearbook of Medical Informatics 2006. Methods Inf Med 2006; 45 Suppl 1: \$159-65.

\section{Keywords}

Health Information Science, Health Informatics, Education, Training, Distance Education
In recent years there has been a growing concern about the availability of well qualified health informatics practitioners. This includes both the need for health informaticians who can implement complex health care information systems, as well experienced managers who can successfully direct such implementations [1]. Indeed, in light of several extensive international efforts to deploy technologies such as electronic patient records (EPRs), a major stumbling block encountered has been the availability of health informaticians with the "right" mix of background and capabilities (i.e. the appropriate knowledge, skills and judgment) to ensure that the large investments made to such efforts can achieve their projected potential [1-3]. In the United States for example, the American Medical Association (AMIA) has promoted an effort to provide rapid training for a large number of health informatics practitioners through their $10 \mathrm{X} 10$ program [4]. In Canada, the issue of availability of qualified practitioners is also of growing concern and a number of organizations are now working to consider what can be done to ease the shortage of trained professionals in both the short and long term [5]. While such contingencies have emerged in order to resolve short-term issues, the question remains "what is the role of academic institutions in training health informaticians with the appropriate mix of knowledge, skills and judgment in order to support large national and international health informatics efforts?". In this paper, we describe an approach to education in health informatics at the University of Victoria that we feel provides an integrated model for training in health informatics across multiple levels, from training of practitioners who will become implementers, developers, managers and evaluators of health care systems, to well qualified and experienced personnel who are poised to take on leadership roles in the field.

\section{History of the School of Health Information Science at the University of Victoria}

The School of Health Information Science at the University of Victoria is one of the oldest and most established programs in health informatics in North America and has been a pioneering influence in health informatics education internationally for twenty-five years $[7,10]$. The School was founded in July 1981 when Denis Protti was appointed Professor and Director. From the beginning of its days, the educational program within the School was based on the premise that education in health informatics should provide stu- 
Kushniruk et al.

dents with a broad range of interdisciplinary skills and competencies related to health informatics. The initial curriculum was based in part on the ACM's Special Interest Group in Biomedical Computing 1979 model curriculum for $\mathrm{Ph} . \mathrm{D}$. programs in the field of health computing. The focus of this recommended curriculum was on preparing graduates for careers in the administration of health care resources, in computer-based education, in biomedical research laboratories and use of health care information systems [7]. This initial curriculum was also influenced by the ACM's model curriculum on Management Information Systems and the Heidelberg/Heilbronn curriculum [14]. The first group of undergraduate health information science graduates received their degrees in May 1986 with all graduates being fully employed. In 1990 the School initiated its graduate program in Health Informatics, which currently includes an on-campus Master of Science degree program, a distributed online Masters program as well as Ph.D. in Health Information Science by special arrangement. In addition, the School has recently added a second undergraduate degree program - a combined major in Health Information and Computer Science. In Canada, the School is the only one of its kind and internationally is one of the few Schools offering a full range of programs and degrees specifically in health informatics, from the Bachelor's level to the Masters and Ph.D. levels (see Table 1 for the programs offered by the School) [7-9]. Currently there are approximately 500 graduates of the School who hold varied positions as health informaticians. Alumni of the school work in varying roles: as analysts, project managers, privacy officers, health information technology policy makers, managers, consultants, directors, chief information officers and academics in Canada and throughout the world. Graduates of the school are highly sought after and statistics on job placements of our students indicates nearly $100 \%$ job placement within positions in health informatics. Upon graduation students typically receive multiple job offers from public and private sector employers in varying health care sectors, among them: acute and long-term care, public health, community and home care and local, provincial and national governments [11]. Indeed, in recent years, the demand for graduates from the School of Health Information Science has continually exceeded the number of graduates, particularly for those prepared at the undergraduate level.

\section{The Need for Interdisáplinary "Holistic" Training and Education in Health Informatics}

The world of health care and health informatics has changed significantly since the early 1980's when computers began to become increasingly used in the health care environment [12]. Advancements and the explosion of knowledge in the biological sciences have led to an explosion of medical and health care knowledge about health and disease moving medicine from an art to a science (e.g. the introduction of guidelines and evidence based practice) [13]. In parallel, improvements in the speed and processing power of computers and the advent of the Internet has led to increased accessibility and availability of information that can be used by health professionals, administrators and health informaticians in decision-making in routine and non-routine health care contexts [12]. Such changes have led to a need for health informaticians with interdisciplinary skills who possess a global understanding of problems and the ability to understand local problems as well as global problems as health information systems become more complex and interrelated.

With changes occurring in the world of health informatics, work on renewing and refining the undergraduate curriculum at the School of Health Information Science began in 2004, with an advisory group struck consisting of health informatics experts, practitioners as well as students and alumni of the School. It was felt that the initial focus of the program on providing interdisciplinary and practical training in a wide range of areas was particularly timely and well suited to the developments taking place in health informatics. In particular, from previous experience, the graduates of the School have been valued in industry for their global approach to problem solving and their interdisciplinary educational background. With the ever increasing rapid changes occurring in the health informatics, the background provided by the programs offered at the School has allowed students to adapt well and assume various leadership roles in health informatics. As a consequence the refined curriculum has retained the

Table 1 Educational programsoffered through the School of Health Information Science

\begin{tabular}{|c|c|}
\hline Undergraduate Degrees & Graduate Degrees \\
\hline $\begin{array}{ll}- & \text { Bachelor of Science - Health Information Science } \\
\text { - } & \text { Bachelor of Science - Combined Major in Computer } \\
& \text { Science and Health Information Science }\end{array}$ & $\begin{array}{ll}\text { - } & \text { Master of Science in Health Information Science } \\
\text { (distributed on-line stream, on-campus stream) } \\
\text { - } \quad \text { Ph.D. in Health Information Science (by special } \\
\text { arrangement) }\end{array}$ \\
\hline
\end{tabular}


The School of Health Information Science at the University of Victoria

essential interdisciplinary nature of the original curriculum, while updating and reviewing the focus of the program. Based on analysis of current trends and the input from faculty, students and the advisory committee, the updated curriculum has focused on the development of several key attributes of health informatics professionals who are graduates of the undergraduate program (advances within our graduate programs will be described in a subsequent section of this paper). A focus was on ensuring that graduates of the program possess specific and highly sought after technical skills, while at the same time having a global "holistic" perspective to health information science. The attributes include the following:

(1) Graduates must follow strong ethical principles and have an understanding of both the positive and negative impacts of health informatics on society. In addition they must be able to apply professional code of conduct espoused by the International Medical Informatics Association.

(2) Graduates must have a broad health care industry and real-world perspective on key aspects of health care system design and evaluation. This should span understanding success and failure of systems at multiple levels, from the end user of systems to the broader organizational and societal levels.

(3) Graduates must possess strong analytical and critical thinking skills, particularly in areas related to understanding selection, deployment and application of research methods in improving the usefulness, usability and appropriate uptake of health informatics innovations.

(4) Graduates must have an integrative perspective to information technology grounded in sound methodological skills focused on continuous quality improvement, ability to design algorithms and to understand advances in system program engineering, design and evaluation methods.

(5) Graduates must possess skills that will allow them to develop innovative approaches to understanding, modeling and re-engineering organizational processes and data and implementing process and technical solutions. In addition, graduates must be used to and capable of continually learning and staying abreast of ever changing trends, technologies and advances emerging from research and development (e.g. consumer empowerment, medical technologies, genomics, bio-informatics etc.)

Courses within the curriculum that were specifically designed to lead to the desired educational outcomes listed above are presented in Figure 1, which details the prescribed four year undergraduate program at the School of Health Information Science (leading to the Bachelor degree in Health Information Science). It should be noted that within the four years of study, 3 fourmonth work terms alternate between course work and co-op work terms (see Figure 1), described in greater detail in the next section.

The School of Health Information Science is in contrast to many international programs (and in particular North American health information science programs) which typically focus either on undergraduate or graduate training and education [6]. Indeed the School of Health Information Science has been one of the leading institutions that has provided both undergraduate and graduate programs, rather than focusing on either undergraduate or graduate education alone. It is felt that there is a need to provide a range of graduates who will be able to address societal needs and requirements for health information systems, as outlined by organizations such as AMIA, from systems analysts and designers to researchers and educators [1].

\section{Experiential Learning in Health Informatics Education and the Role of Research in the Health Informatics Curri- culum}

An emphasis of the health informatics program at the University of Victoria has been its focus on experiential learning. Students are required to take part in three four-month work terms staggered throughout the undergraduate degree program. The intent of the work terms is to complement the learning taking place in class rooms with practical experience in the field. Our undergraduate students have held a variety of exciting and increasingly responsible co-op work term positions in a wide range of settings ranging from hospital informatics departments to private healthcare software companies, government agencies and health ministries, both provincially and federally. At the same time as emphasizing strong connections with the healthcare industry, through the co-op program, the School has also placed a strong and increasing emphasis on graduate and postgraduate education and research. Both are seen as complementary in order to ensure a School perspective that is relevant to industry but that at the same time takes into account the most recent advances in health informatics research [8]. Indeed a recent development within the School is the introduction of optional co-op terms for graduate students who wish to gain experience in real-world settings to complement their graduate training, gained through up to two coop work terms to be completed during either Masters or Doctoral studies. 
Kushniruk et al.

\begin{tabular}{|c|c|c|c|}
\hline \multirow{2}{*}{$\begin{array}{l}\text { First Year: Health Imformation Science } \\
\text { SEPT. - DEC. }\end{array}$} & \multicolumn{2}{|l|}{15.0 units } & \\
\hline & JAN. - APRIL & \multicolumn{2}{|l|}{ MAY - AUGUST } \\
\hline $\begin{array}{l}\text { Cousse: } \\
\text { HIHF } 172 \text { Introduction to Heakh Informatics } \\
\text { Applications } \\
\text { CSC } 110 \text { Fundamental of Programming I } \\
\text { ENGL } 115 \text { or ENGL } 135 \\
\text { PE } 141 \text { or BIOC } 102 \text { or BIOL 150A or BIOL 190A } \\
\text { ELECTIVE }\end{array}$ & $\begin{array}{l}\text { Cousse: } \\
\text { HINF } 140 \text { The Govenance and Structure of the Health } \\
\text { Care Systems } \\
\text { CSC 15 Fundamentals of Programming II } \\
\text { MATH } 151 \text { Finite Mathematics } \\
\text { ELECTIVE }\end{array}$ & $\frac{\text { Cousse: }}{\text { NONE }}$ & $\begin{array}{l}\text { Legpnd: } \\
\text { HINF = Health Infomation } \\
\text { Scienve } \\
\text { CSC = Compuler Science } \\
\text { ENGL = English } \\
\text { PE = Physical Education } \\
\text { BIOC = Biochemisthy } \\
\text { BIOL = Biology }\end{array}$ \\
\hline \multicolumn{4}{|c|}{ Second Year: $\quad 15.0$ Units } \\
\hline SEPT. - DEC. & JAN. - APRIL & \multicolumn{2}{|l|}{ MAY - AUGUST } \\
\hline $\begin{array}{l}\text { Course: } \\
\text { HIINF 200 Principles of Health Database Design } \\
\text { SINF } 230 \text { Organizational Behaviour and Change Management } \\
\text { STAT 252 } \\
\text { ELECTVE } \\
\text { ELECTIVE }\end{array}$ & $\begin{array}{l}\text { Course: } \\
\text { HINF 201 Database Managementand Development for } \\
\text { Health Care Systems } \\
\text { HINF } 265 \text { Health Care Delivery and Organizational } \\
\text { Models } \\
\text { HINF } 230 \text { Biomedical Fundamentals } \\
\text { ELECTIVE } \\
\text { ELECTIVE }\end{array}$ & $\begin{array}{l}\text { Couse: } \\
\text { WORK TERM \# } 1\end{array}$ & $\frac{\text { Legpnd: }}{\text { STAT }=\text { Statistics }}$ \\
\hline \multicolumn{4}{|l|}{ Third Year: } \\
\hline SEPT. - DEC. & JAN. - APRIL & \multicolumn{2}{|l|}{ MAY - AUGUST } \\
\hline 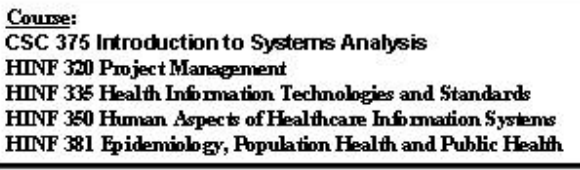 & $\begin{array}{l}\text { Cousse: } \\
\text { WORK TERM \# } 2\end{array}$ & \multicolumn{2}{|c|}{ 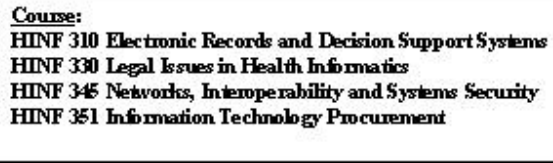 } \\
\hline \multicolumn{4}{|l|}{ Fourth Year: } \\
\hline SEPT. - DEC. & JAN - APRIL & \multicolumn{2}{|l|}{ MAY - AUGUST } \\
\hline $\begin{array}{l}\text { Course: } \\
\text { WORK TERM \# } 3\end{array}$ & 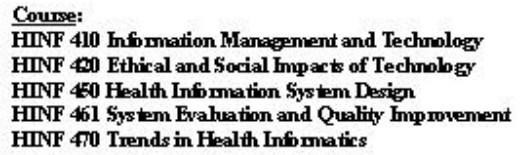 & \multicolumn{2}{|l|}{$\begin{array}{l}\text { Counse: } \\
\text { SENIOR ELECTIVE } \\
\text { SENIOR ELECTIVE } \\
\text { SENIOR ELECTIVE } \\
\text { SENIOR ELECTVE } \\
\text { SENIOR ELECTIVE }\end{array}$} \\
\hline
\end{tabular}

Fig. 1 Model Undergraduate Currical um in Health Information Science at the University of Victoria

In addition, linkage between research and both undergraduate and graduate training is accomplished through teaching by faculty whose industry and research experience is significant. The School's faculty have worked in various industry roles ranging from clinical positions, project management, information officer and industry to government consulting. Teaching includes integration of case studies from real life situations, group projects with local health care organizations, and the introduction of students to real world work contexts and issues through invited presentations from a range of health informatics practitioners, managers and government officials to complement traditional classroom training. More recently, there has been a demand for further training of practicing information technology and health professionals in health informatics in Canada. In response the University of Victoria has developed an on-line graduate program in health informatics targeted towards practicing professionals, described in the next section.

\section{Towards a Distributed Model of Health Informatics Education}

In 2002, the Office of Learning Technology (OLT) at the Federal Ministry of Human Resources and Skills Development Canada co-funded a 2-year initiative to build health informatics capacity for professionals in health settings through alternative delivery approaches. The consortium consisted of the School as the lead, the Health Telematics Unit at the University of Calgary (UofC), the Centre for Health Evidence at the University of Alberta (UofA), the Division of Continuing Medical Education at the University of British Columbia (UBC), COACH-Canada's Health Informatics Association, and a private company called ShirWin Knowledge and Learning Systems in Alberta. Ten learning modules on various health informatics topics were 
developed by the four universities drawing on their respective expertise. Different delivery modalities were explored with these modules including online asynchronous interactions, mixed interaction formats, intensive face-toface workshops and synchronous virtual classes. The modules were piloted with small groups of learners in 2003/04 to determine their feasibility and logistics with satisfactory results.

In summer of 2004 the School obtained approval from the Board of Governors to introduce a distributed on-line MSc stream drawing on the learning modules, collaboration and experiences from the OLT initiative. The current distributed MSc stream is a part-time program aimed at working professionals with one or more years of health or IT experience. Students enrolled in this program are required to complete 10 courses and a major project over two years. In addition to the regular University of Victoria courses and faculty mentors, the program includes six online courses and eight senior faculty from UofC, UofA, UBC and SFU (Simon Fraser University). Most courses are offered online through a combination of synchronous and asynchronous modes, except for two capstone courses offered each summer as 2-week intensive faceto-face workshops held at the University of Victoria followed by 2-week online interactions. An example of the distributed MSc program schedule and course offering is shown in Figure 2.

The distributed stream began in January 2005 and presently has a cohort of 23 students with varying backgrounds including physicians, nurses, pharmacists and IT professionals working mostly in the health sector. Several students have funding support and/or protected time from their employers to enroll in the program. In June 2005 we completed the first ever 2-week intensive workshop at the University of Victoria in health information management and information systems design. Feedback from the students have been extremely positive not only of the quality of the course content but also the opportunity to network with faculty and peers as a learning community. Students are now starting to plan their research project as part of the degree requirement, which has to be work related and should benefit the organization in tangible ways. Examples of such projects are privacy issues in genomics laboratory information systems, usability study of emergency triage and guidelines sy- stems, and e-health strategy for First Nations communities. A supervisory committee consisting of two faculty mentors and an employer representative is organized for each student to ensure the rigor and relevance of the research, and the timely completion of the project.

\section{A Collaborative Advanced HI Research Training Program}

In addition to launching a distributed MSc program in Health Informatics, in 2002 a consortium of eight Canadian universities was awarded a 6-year grant from the Canadian Institutes of Health Research to establish a collaborative health informatics research training program. The eight partners are the Universities of Calgary, Toronto, Waterloo, McMaster, McGill, Sherbrooke and Dalhousie, with the University of Victoria as the lead. The overall aim of this program is to increase research capacity in health informatics at the $\mathrm{PhD}$, postdoctoral and practitioner levels in Canada. The specific objectives are to: (1) offer research learning experiences to trainees not obtainable from local programs; (2)

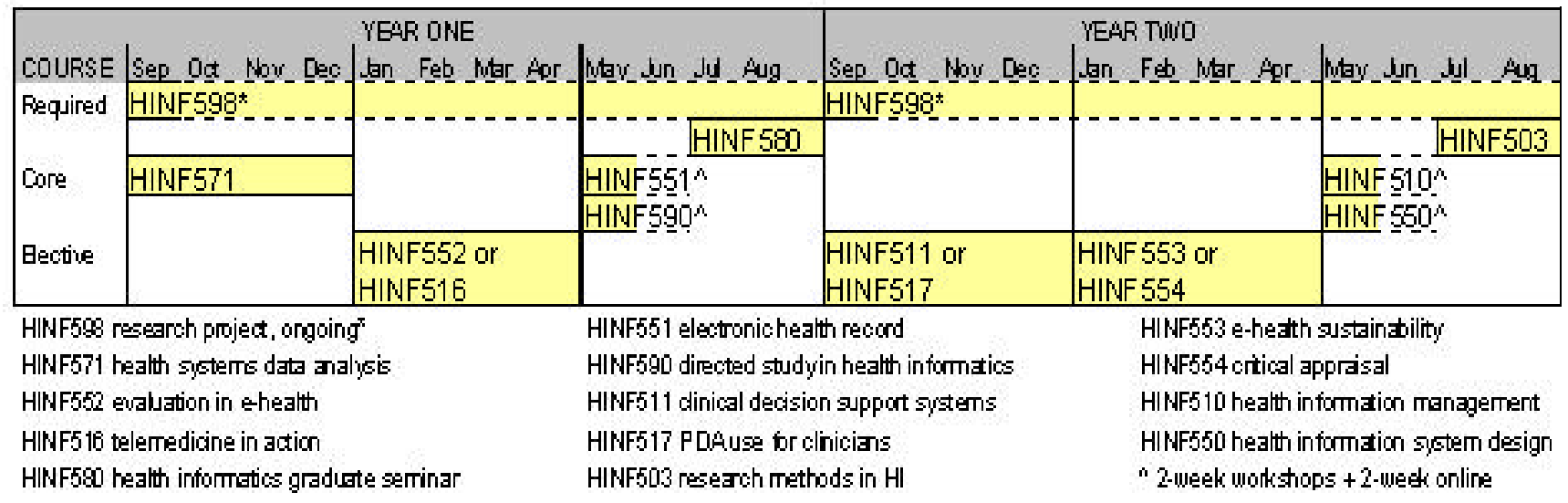

Fig. 2 A sample schedule for the distributed MScprograms 
Kushniruk et al.

strengthen collaboration among partner institutions in health informatics education and research; (3) build a virtual community that is actively engaged in health informatics research, education and practice; (4) assume a leadership/ facilitation role as a credible academic health informatics community in Canada. The program has 1 intake of trainees once every two years each 20 months in duration [5].

The current intake has three online Research Learning Experience (RLE) modules comprised of regular virtual classes, annual on-campus workshops and face-to-face meetings at health informatics related conferences. The trainees are grouped into three minicohorts each focused on one thematic area to encourage collaboration and teamwork across the eight universities. The current three themes are primary care informatics, e-health policy and evaluation, and knowledge management. Working with faculty researchers as mentors and practitioners as collaborators, the trainees are required to produce tangible outputs that include peer-reviewed publications, conference papers, research proposals, business cases and system prototypes. An example of the 2005-06 intake for the 20month program is shown in Figure 3. There are currently $35 \mathrm{PhD}$, postdoctoral and practitioner trainees in the 2nd cohort that started in January 2005. Under the guidance of 15 faculty mentors from the eight universities, the trainees completed a 12-week RLE01 module called "Frontiers in Health Informatics Research" through biweekly virtual classes that reviewed the latest Health Informatics research areas, trends and challenges. In May 2005 a 3-day face-to-face workshop was held at Dalhousie University as part of RLE02 called "Health Informatics Research Projects" where trainees, mentors and collaborators met to exchange ideas and discuss projects. Presently, the mini-cohorts are conducting literature/systematic reviews and designing and evaluating information system prototypes in specific health informatics areas as the $2^{\text {nd }}$ part of RLE02. Examples include the impacts of PDA's on medical training, CPOE and patient safety, successful primary care EMR implementation factors, e-learning interventions in healthcare, web-based head-injury information for parents, and evidence retrieval algorithms for progress notes. In addition, each trainee is planning a $2^{\text {nd }}$ tangible output for Dec 2006 that can be a PhD dissertation, research report, journal publication or system prototype. A follow-up annual workshop is planned for May 2006 in Calgary, Alberta to provide an oppor- tunity for the trainees to present and share their research findings. The $3^{\text {rd }}$ RLE, scheduled for Sep2005-Apr2006, consists of monthly virtual seminars for trainees to discuss their research-inprogress with real-time critique and feedback from faculty mentors and collaborators.

\section{Condusions}

The School of Health Information Science at the University has provided an integrated approach to health information science training for over twenty years. The approach taken has been based on concept that health informaticians need to possess specialized skills in areas related to information technology, organizational science and health studies [15]. In addition, it is the philosophy of the School that students must develop strong integrative and "holistic" capabilities and skills in order to successfully keep up with and provide leadership in the ever changing field of health informatics. Towards this end, the School has recently reviewed and updated its undergraduate educational programs and has worked towards developing and expanding its graduate training through new programs and initiatives, including the Distributed on-line Masters program in Health

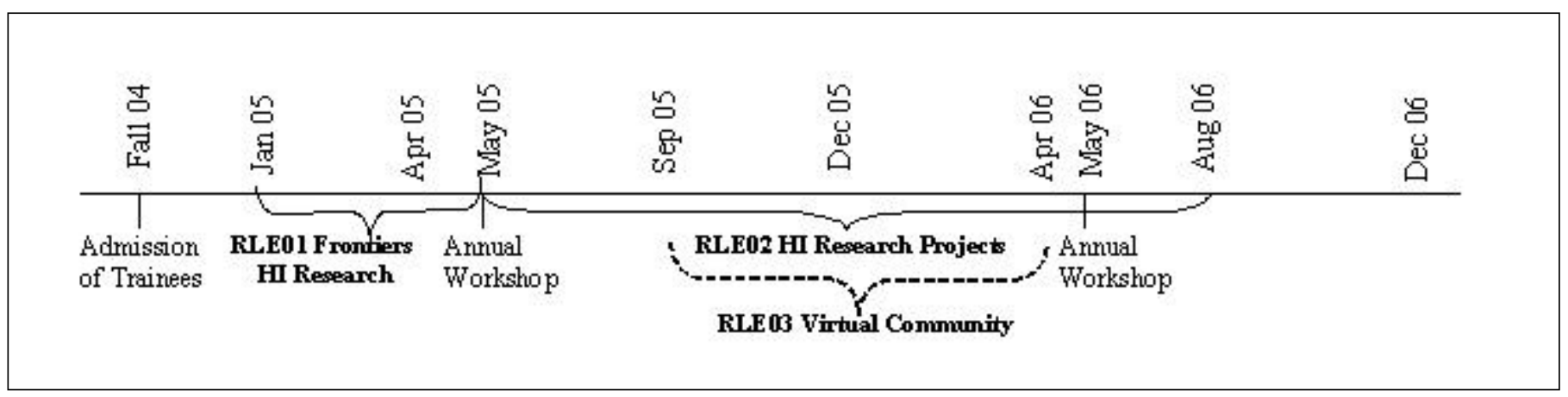

Fig. 3 The 2005-06 intake showing the timeline for the three RLE's 
Information Science (the first of its kind in Canada) and a leadership role in the pan-Canadian advanced Health Informatics Research Training Program. Current planning at the School will includes further and continued work in integrating graduate level and research activities within the School with theoretical and applied activities and undergraduate training in order to address the growing need for health informatics professionals who will possess the skills needed to successfully carry out the emerging health informatics initiatives, both within Canada and internationally. It is also hoped the experiences and models developed at the School of Health Information could help serve other institutions in development of models for integrative health informatics educational and training programs.

\section{References}

1. Brittain JM, Norris AC. Delivery of health informatics education and training. Health Lib Rev
2000; 17(3), 117-28.

2. Murphy J, Stramer K, Clamp S, Grubb P, Goslan J, Davis $\mathrm{S}$. Health informatics education for clinicians and managers - What's holding up progress? Int J Med Inf 2004; 73: 205-15.

3. Hovenga EJS. Globalization of health and medical informatics education - What are the issues? Int J Med Inf 2004; 73-101-9.

4. AMIA. 10,000 trained by 2010. 2005; http:// www.amia.org/10x10

5. Lau F. Health informatics education in Canada What's ahead? Electronic Healthcare 2001; 1(2), 46-51.

6. Friedman CP, Altman RB, Kohane IS, McCormick KA, Miller PL, Ozbolt JG, et al. Training the Next Generation of Informaticians: The Impact of "BISTI" and Bioinformatics-A Report from the American College of Medical Informatics. JAMIA 2004; 11, 167-72.

7. Wood L. The School of Health Information Science: Beginnings. Health Care Inf Manag Comm 2002; 4: 14-16.

8. Huynh A, Lau F. Reflections on the HINF CO-OP education program at the University of Victoria. Health Care Inf Manag Comm 2002; 4: 54-55.

9. Coward P. New initiatives at the school of health information science. Health Care Inf Manag Comm 2002; 4: 22-3.

10. Borycki EM. Celebrating forty years of excellence in health informatics. Health Care Inf Manag Comm 2005; $3: 18-9$.

11. School of Health Information Science. $20^{\text {th }}$ Anniversary Special Edition Annual Report, 2002.

12. Shortliffe EH, Blois MS. The computer meets medicine and biology: Emergence of a discipline. In: Shortliffe EH, Perreault LE, Wiederhold G, Fagan LM, editors. Medical informatics: Computer applications in health care and biomedicine. 2nd ed. New York: Springer; 2001. p. 3-40.

13. McLaughlin CP, Kaluzny AD. Defining quality improvement: Past, present and future. In: McLaughlin CP, Kaluzny AD, editors. Continuous quality improvement in health care: Theory, implementation and applications. 2nd ed. Aspen: Gaithersburg, Maryland; 1999. p. 3-33.

14. Leven FJ, Knaup P, Schmidt D, Wetter T. Medical informatics at Heidelberg/Heilbronn: Statusevaluation-new challenges in a specialized curriculum for medical informatics after thirty years of evolution. Int J Med Inform 2004; 73: 117-25.

15. Protti D, Fisher P. Health informatics at the University of Victoria. Yearbook of Medical Informatics, Schattauer;1996.

\section{Correspondence to:}

Professor Andre Kushniruk

School of Health Information Science

University of Victoria

Human and Social Development Building, Room A2O2

3800 Finnerty (Ring) Road

Victoria, British Columbia V8P 502

Canada

E-mail: andrek@uvic.ca 